\title{
POR polymorphisms are associated with 21 hydroxylase deficiency
}

\author{
F. Pecori Giraldi ${ }^{1,2} \cdot$ S. Einaudi ${ }^{3} \cdot$ A. Sesta ${ }^{2} \cdot$ F. Verna $^{3} \cdot$ M. Messina ${ }^{4} \cdot$ C. Manieri ${ }^{5} \cdot$ E. Menegatti $^{6} \cdot$ L. Ghizzoni $^{5}$
}

Received: 19 August 2020 / Accepted: 12 December 2020 / Published online: 5 March 2021

(c) The Author(s) 2021

\begin{abstract}
Purpose Genotype-phenotype correlation in congenital 21 hydroxylase deficiency is strong but by no means absolute. Indeed, clinical and hormonal features may vary among patients carrying similar CYP21A2 mutations, suggesting that modifier genes may contribute to the phenotype. Aim of the present study was to evaluate whether polymorphisms in the p450 oxidoreductase $(P O R)$ gene may affect clinical features in patients with 21 hydroxylase deficiency

Methods Sequencing of the POR gene was performed in 96 patients with 21 hydroxylase deficiency (49 classic, 47 nonclassic) and 43 control subjects.

Results Prevalence of $P O R$ polymorphisms in patients with 21 hydroxylase was comparable to controls and known databases. The rs 2228104 polymorphism was more frequently associated with non-classic vs classic 21 hydroxylase deficiency (allelic risk 7.09; 95\% C.I. 1.4-29.5, $p<0.05$ ). Classic 21 hydroxylase-deficient carriers of the minor allele in the rs2286822/ rs2286823 haplotype presented more frequently the salt-wasting form (allelic risk 1.375; 95\% C.I. 1.138-1.137), more severe Prader stage at birth (allelic risk 3.85; 95\% C.I. 3.78-3.92), higher ACTH levels, and younger age at diagnosis.

Conclusions Polymorphisms in the POR gene are associated with clinical features of 21 hydroxylase deficiency both as regards predisposition to classic vs non-classic forms and severity of classic adrenal hyperplasia.
\end{abstract}

Keywords POR $\cdot$ Congenital adrenal hyperplasia $\cdot$ CYP21A2 $\cdot \mathrm{SNP} \cdot$ Genotype-phenotype correlation

\section{Introduction}

Congenital adrenal hyperplasia due to 21 hydroxylase deficiency ranks among the most frequent endocrine genetic defects, and considerable efforts have been expended to

F. Pecori Giraldi

francesca.pecorigiraldi@unimi.it

1 Department Clinical Sciences and Community Health, University of Milan, Milan, Italy

2 Istituto Auxologico Italiano IRCCS, Neuroendocrinology Research Laboratory, Milan, Italy

3 Department Pediatric Endocrinology, Azienda Ospedaliera Città della Salute e della Scienza, University of Turin, Turin, Italy

4 Clinical Pathology and Experimental Medicine Unit, Department Clinical and Biological Sciences, University of Turin, Turin, Italy

5 Division of Endocrinology, Diabetes and Metabolism, Department Medical Sciences, University of Turin, Turin, Italy

6 Department Medical Genetics, Azienda Ospedaliera Città della Salute e della Scienza, University of Turin, Turin, Italy understand its pathophysiology and ameliorate diagnostic and therapeutic strategies. Clinical presentation depends on the severity of the underlying enzyme defect and, in patients who are compound heterozygotes for CYP21A2 mutations, phenotype usually correlates with the less severely mutated allele and residual 21 hydroxylase activity [1]. However, genotype-phenotype correlation is by no means absolute [1-3]. In fact, a recent study on over 1500 families demonstrated that direct genotype-phenotype correlation could be observed in less than 50\% of CYP21A2 genotypes [4]. Furthermore, sib pairs carrying identical CYP21A2 mutations but presenting different phenotypes, i.e., salt-wasting, simple virilizing or even only mild hyperandrogenism, have also been reported $[5,6]$.

It is conceivable that other factors may influence 21 hydroxylase enzyme activity and contribute to the variability of clinical features among different enzyme defects. $\mathrm{P} 450$ oxidoreductase (POR), a flavoprotein involved in several microsomal reactions including 21 hydroxylation [7], is one of the most likely candidates. Interest in POR stems for the fact that mutations in $P O R$ lead to deranged steroidogenesis with sexual ambiguity and cortisol deficiency $[8,9]$. 
In addition to these enzyme-disrupting mutations, the $P O R$ gene is highly polymorphic and variants have been associated with altered 21 hydroxylase and 17 hydroxylase/17,20 lyase activity [7].

Aim of the present study is to evaluate whether genomic variants in $P O R$ contribute to the phenotype of patients with congenital adrenal hyperplasia due to CYP21A2 mutations. Associations between polymorphisms and clinical features will aid in the understanding of 21 hydroxylase defects pathophysiology and, hopefully, lead to the development of individualized treatment strategies.

\section{Methods}

\section{Patients}

Ninety-six Caucasian patients with classic (49 patients, 28 females, 21 males) and non-classic (47 patients, 21 females, 26 males) congenital adrenal hyperplasia due to 21 hydroxylase deficiency were studied over the past 2 decades at the Azienda Ospedaliera Città della Salute e della Scienza in Turin. Data relative to presentation and treatment were collected for statistical analysis. Hormonal and clinical assessments were performed as described in $[3,10]$. Age at diagnosis was $15.6 \pm 1.71$ days in patients with classic adrenal hyperplasia and $7.93 \pm 0.63$ for pediatric and $37.4 \pm 3.1$ years for adult patients with non-classic 21 hydroxylase deficiency, respectively. Patients with classic adrenal hyperplasia were classified as simple virilising or salt-wasting based on clinical and biochemical signs, e.g., dehydration, failure to thrive, hyponatriemia, and hyperkalemia. Salt wasting was present in $85 \%$ of patients with classic 21 hydroxylase deficiency (77\% of females and $95 \%$ of males, N.S.), whereas hypoglycemia was detected in $8 \%$. Among patients with the non-classic form, premature pubarche was present in 20 (19 females and 1 male), precocious puberty in 7 (all females), hirsutism alone in 9 females (43\%), and acne and hirsutism in 5 females (24\%). The remaining patients were asymptomatic relatives of patients, detected while performing family studies. In parallel, 43 subjects, 22 women and 21 men, all wild-type for $C Y P 21 A 2$, were used as controls for $P O R$ sequencing.

\section{CYP21A2 sequencing}

Total genomic DNA was extracted from leukocytes collected in EDTA-coated tubes, using the QIAamp DNA Blood Midi Kit (Qiagen, Milan, Italy), according to the manufacturer's instructions. Gene deletions and large gene conversion were evaluated by Southern blotting analysis with TaqI digestion, whereas the most common and pseudogene-derived point mutations were detected by multiplex minisequencing using
CYP21A2-specific long-range PCR as template (reference sequence NM_000500.9). Chimeric genes were identified by long-range PCR using appropriate, specific primers for CYP21P/CYP21 and CYP21/CYP21P chimeras, respectively. Obtained amplicons were further characterized by multiplex minisequencing mutation analysis [10].

Patients with classic 21 hydroxylase deficiency carried 11 different $C Y P 21 A 2$ mutations with $20 \%$ presenting the deletion/c.*13G $>$ A genotype, $16 \%$ the deletion/I172N genotype, $12 \%$ the homozygous c. $* 13 \mathrm{G}>$ A genotype, $8 \%$ the c.*13G $>\mathrm{A} / \mathrm{Q} 318 \mathrm{X}$ genotype, and $6 \%$ the deletion/ R356W genotype (further details are shown in supplementary Table 1; https://doi.org/10.13130/RD_UNIMI/DNZMA $0)$. Among patients with non-classic adrenal hyperplasia, $36 \%$ presented the V2811/V281L genotype, $17 \%$ the V281L/ P453S genotype, and 23\% the V281L/I172N and V281L/ deletion genotypes (further details are shown in Supplementary Table 1). CYP21A2 mutations were grouped according to severity of the enzyme defect $[5,11]$ : no residual activity = group O (deletion, gene conversion, Q318X, R356W), approx. $1 \%$ residual activity $=$ group A $($ c. $* 13 \mathrm{G}>\mathrm{A}, \mathrm{N} 381 \mathrm{I})$, $2-3 \%$ residual activity $=$ group $B(I 172 \mathrm{~N}, \mathrm{R} 341 \mathrm{P})$, and $>30 \%$ residual activity $=$ group C $(\mathrm{V} 281 \mathrm{~L}, \mathrm{P} 30 \mathrm{~L}, \mathrm{P} 453 \mathrm{~S}, \mathrm{~L} 288 \mathrm{~F})$. Patients were categorized according to the less severe mutation group [11]. As expected, patients with classic adrenal hyperplasia were mostly group O (18\%), A (44\%), and B (30\%), whereas patients with non-classic adrenal hyperplasia were group C (supplementary Table 1 ).

\section{POR sequencing}

Primers specific for POR (NG_023211.1, 71,754 bp; exons 1-15) were designed using Primer3 [12] to include at least 100 bases of flanking intronic DNA. PCR amplification with $100 \mathrm{ng}$ genomic DNA and GoTAq DNA Polymerase (Promega, Madinson WI) was performed at high touchdown cycling conditions ( 14 cycles with $0.5^{\circ} \mathrm{C}$ decrease at each cycle from $65{ }^{\circ} \mathrm{C}$ to $58.5^{\circ} \mathrm{C}$, starting with $95^{\circ} \mathrm{C}$ for $5 \mathrm{~min}$ ) followed by 25 cycles at $58{ }^{\circ} \mathrm{C}$ annealing. POR sequences were compared to reference ENSG00000127948.9 and variants identified. Variants were searched on EntrezGene, Human Gene Mutation Database (HGMD), Human Genome Variation Database (HGVbase), Ensembl, and dbSNP. Significance of identified variants was assessed using Mutation taster [13], Mutation assessor [14], SIFT [15], and FATHMM [16]. Sequence variants were interpreted according to the American College of Medical Genetics and Genomics and the Association for Molecular Pathology 2015 recommendation [17]. 
Table 1 POR polymorphisms detected in patients with 21 hydroxylase deficiency and control subjects

\begin{tabular}{|c|c|c|c|c|c|c|c|c|c|c|c|c|c|c|}
\hline \multirow[t]{2}{*}{ SNP } & \multirow[t]{2}{*}{ Location } & \multirow[t]{2}{*}{ MAF } & \multirow[t]{2}{*}{ In silico } & \multicolumn{3}{|c|}{$\begin{array}{l}\text { Prevalence in } \\
\text { controls }\end{array}$} & \multirow{2}{*}{$\begin{array}{l}\text { HWE } \\
p\end{array}$} & \multicolumn{3}{|c|}{$\begin{array}{l}\text { Prevalence in classic } \\
\mathrm{CAH}\end{array}$} & \multicolumn{3}{|c|}{$\begin{array}{l}\text { Prevalence in non- } \\
\text { classic CAH }\end{array}$} & \multirow{2}{*}{$\begin{array}{l}\text { Classic } \\
\text { vs non- } \\
\text { classic }\end{array}$} \\
\hline & & & & wt & het & homo & & wt & het & homo & wt & het & homo & \\
\hline rs1135612 & exon $5 \mathrm{~A} / \mathrm{G}$ & 0.24 & synon & 51 & 35 & 14 & 0.21 & 59 & 31 & 10 & 70 & 26 & 4 & N.S \\
\hline rs41301394§ & intron $8 \mathrm{C} / \mathrm{T}$ & 0.29 & & 56 & 37 & 7 & 0.88 & 47 & 39 & 14 & 53 & 43 & 4 & N.S \\
\hline rs4732516 & intron $10 \mathrm{G} / \mathrm{C}$ & 0.06 & & 88 & 12 & 0 & 0.68 & 94 & 4 & 2 & 85 & 15 & 0 & N.S \\
\hline rs $2286822^{*}$ & intron $11 \mathrm{C} / \mathrm{T}$ & 0.30 & & 42 & 44 & 14 & 0.78 & 45 & 47 & 8 & 62 & 30 & 8 & N.S \\
\hline rs2286823* & intron $11 \mathrm{G} / \mathrm{A}$ & 0.31 & & 44 & 45 & 14 & 0.78 & 34 & 52 & 14 & 62 & 31 & 7 & N.S \\
\hline rs2228104 & exon $13 \mathrm{C} / \mathrm{T}$ & 0.06 & synon & 88 & 12 & 0 & 0.68 & 96 & 4 & 0 & 77 & 23 & 0 & $p<0.05$ \\
\hline rs1057868§ & exon $13 \mathrm{C} / \mathrm{T}$ & 0.28 & A503V & 53 & 37 & 10 & 0.62 & 51 & 35 & 14 & 59 & 38 & 3 & N.S \\
\hline rs1057870 & exon $14 \mathrm{G} / \mathrm{A}$ & 0.32 & synon & 49 & 44 & 7 & 0.64 & 49 & 45 & 6 & 40 & 38 & 22 & N.S \\
\hline
\end{tabular}

Prevalence is reported in \%

SNPs in LD are identified by * (block 1) and § (block 2)

$M A F$ minor allele frequency, synon synonymous variant, $w t$ wild-type, het heterozygous carriers, homo homozygous carriers, $H W E$ HardyWeinberg Equilibrium

\section{Statistics}

Variant distribution and deviation from Hardy-Weinberg equilibrium were assessed in controls. Linkage disequilibrium (i.e., D' and $r^{2}$ ) and haplotype frequencies were computed by Haploview 4.1, Broad Institute, Cambridge, MA [18]. Association between allelic risk and dichotomic phenotypic features was first tested by Pearson's chi squared test assuming no model effect and allelic/genotypic risk calculated; significant associations were subsequently tested by Score test for dominant effect model, in view of summary data. Cochrane-Armitage test for trend was used for ordered categorical variables. Mann-Whitney or Kruskal-Wallis ANOVA were used to determine differences in continuous parameters between variant/haplotype carriers and wild-type. Furthermore, logistic regression analysis was used to assess associations between single-nucleotide polymorphisms (SNP) and continuous variables taking covariates such as sex into account. Bonferroni's correction for multiple comparisons was applied where appropriate. The sample size allowed detection of $\mathrm{OR}>3.0$ with at least $80 \%$ potency, given minor allele frequency (MAF) greater than 5\% and 0.05 two-sided alfa [19]. Data are reported as mean \pm S.E.M. or Odds ratio (O.R.) with $95 \%$ confidence interval (95\% C.I.)

\section{Results}

\section{POR polymorphisms}

Eight different known $P O R$ single-nucleotide polymorphisms with MAF greater than $5 \%$ were identified (see Table 1). The four intronic variants are benign as assessed by the above-mentioned pathogenicity prediction software; as regards proximity to intron-exon boundaries, rs41301394 is located 35 bp upstream to exon 9 , rs4732516 is located 13 bp upstream to exon 11, and rs 2286822 and rs 2286823 are located 12 and $20 \mathrm{bp}$, respectively, downstream to exon 11. Variants rs1135612, rs2228104, and rs 1057870 are synonymous SNPs (rs1135612: p.P129=, rs2228104: p.A485 =; rs 1057870: p.s572=), whereas rs1057868 is a missense p.A503V variant (previously reported as $P O R^{*} 28$ ). Additional intronic (rs371932012, rs72557932, and rs72557956) and exonic SNPs (rs10262966, rs41295381, rs1585129713, rs11540674, rs72557941, rs377500167, rs150414675, rs370823127, rs375387233, rs1320059073, and rs145782750) occurred in individual patients or controls. MAF for all SNPs corresponded to data reported in available databases (www.ncbi.nlm.nih.gov/snp). The eight major SNPs were in Hardy-Weinberg equilibrium in controls and no differences in sex distribution were observed in either patients or controls. 
Two haplotype blocks were identified, each comprising two SNPs (Supplemental Fig. 1; https://doi.org/10.13130/ RD_UNIMI/DNZMA0): rs2268622 and rs2268623 with $r^{2} 0.966$ and D' 1.0 (95\% C.I. 0.96-1.0), while rs 2057868 and rs 41301394 presented $r^{2} 0.88$ and D' 0.963 (95\% C.I. 0.90-0.99).

\section{Impact of POR polymorphisms on prevalence of classic and non-classic $\mathbf{2 1}$ hydroxylase deficiency}

Prevalence of the rs2228104 polymorphism was significantly higher among patients with non-classic compared with patients with classic 21 hydroxylase deficiency $(11.7 \%$ vs $2.0 \%, p<0.05$, see Table 1 for genotype frequency) and the allelic risk associated with non-classic $\mathrm{CAH}$ was equal to 7.09 (95\% C.I. 1.37-29.52, $p<0.05$ ). In keeping, the T allele was present in 11.0 vs $2.17 \%(p<0.05)$ of patients with group $\mathrm{C}$ mutations and allelic risk associated with group C was 5.91 (95\% C.I. 1.19-25.81, $p<0.05$; Supplemental Table 2).

None of the other POR polymorphisms or haplotypes were associated with increased risk of either classic or nonclassic 21 hydroxylase deficiency (Table 1) or CYP21A2 defect grouping (Supplemental Table 2).

\section{Impact of POR polymorphisms on clinical features of classic and non-classic 21 hydroxylase deficiency}

Significant differences as regards clinical presentation in patients with classic congenital hyperplasia were observed according to the POR rs2268622/23 haplotype. In fact, carriers of the minor alleles were significantly younger at diagnosis $(11.8 \pm 1.37$ vs $20.0 \pm 4.03$ days, $p<0.05)$ (Fig. 1 ) and presented higher plasma ACTH levels $(416.8 \pm 82.81 \mathrm{vs}$ $148.6 \pm 18.43 \mathrm{pg} / \mathrm{ml}, p<0.05$, Fig. 1) compared to children with classic CAH carrying the wild-type CC/GG alleles. Logistic regression confirmed association between the rs2268622/23 haplotype and age (coefficient $-0.08, \mathrm{p}<0.05$ ) and ACTH levels at diagnosis (coefficient 0.10, $p<0.05$ ), regardless of sex of the patient. Indeed, age at diagnosis was comparable among males and females wild-type for the $P O R$ wild-type CC/GG alleles $(19.1 \pm 2.72$ vs $21.4 \pm 2.31$ days, respectively, N.S.) and carriers of the rs2268622/23 haplotype ( $13.5 \pm 1.65$ vs $12.4 \pm 2.17$ days, respectively, N.S.). Furthermore, $96 \%$ of minor allele carriers presented saltwasting at birth (Score test for dominant model 6.29, $p<0.01$; allelic risk 1.375; 95\% C.I. 1.138-1.137). In addition, Prader stage was more severe among girls carrying the minor vs wild-type alleles (Chi-square for trend 4.7, $p<0.05$, Fig. 1) as was the risk for severe (i.e., stages IV and V) vs mild Prader stage (i.e., stages I, II, and III) at birth (score test for dominant model 6.0, $p<0.05$; allelic risk 3.85 ; $95 \%$ C.I. $3.78-3.92$ ). The rs $2268622 / 23$ haplotype was equally distributed among different $C Y P 21 A 2$ defect groups: $70 \%, 62 \%$, and $53 \%$, respectively, among group O, A, and B (Chi-square 4.96 with 2 d.f., N.S.); none of the 3 patients in group C carried the rs2268622/23 haplotype.

In patients with non-classic 21 hydroxylase deficiency, no differences in phenotypic features could be detected between carriers of the POR rs2268622/23 haplotype and wild-type patients. None of the other $P O R$ polymorphisms or the 868/194 haplotype were associated with clinical features of classic or non-classic 21 hydroxylase deficiency.

\section{Discussion}

The present study shows that polymorphisms in the POR gene are associated with the phenotype of patients with congenital adrenal hyperplasia, a novel finding in the pathophysiology of 21 hydroxylase deficiency.

POR (cytochrome P450 oxidoreductase) is a flavoprotein which subserves several microsomal enzymatic reactions, most notably those deputized to drug metabolism and steroid biosynthesis [20]. In the context of adrenal steroidogenesis, POR contributes to 21 hydroxylase, 17 hydroxylase, and
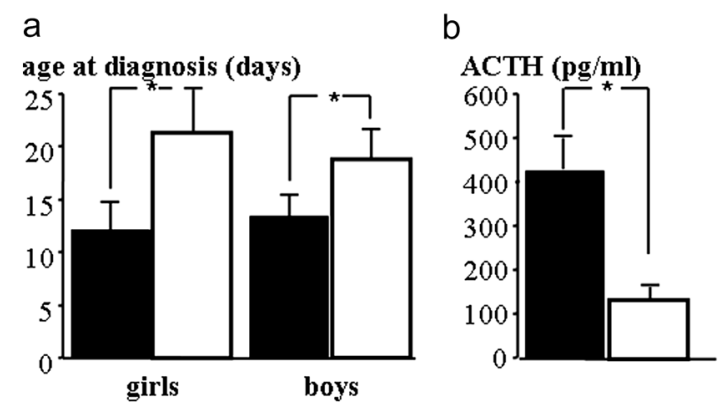

C

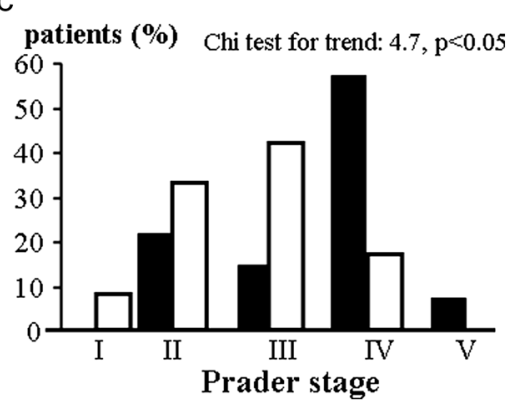

Fig. 1 Age at first dosing, ACTH levels, and Prader stage according to $P O R$ rs2268622/23 haplotype. a Age at diagnosis in girls and boys carrying minor (black) or wild-type (white) POR rs2268622/23 alleles. b Plasma ACTH levels in children carrying minor (black) or wild-type (white) alleles. c Severity of Prader stage at birth in girls carrying minor (black) or wild-type (white) alleles. ${ }^{*} p<0.05$ 
17,20 lyase activity; indeed, mutations in POR may lead to sexual ambiguity and adrenal insufficiency, i.e., Antley-Bixler syndrome with genital abnormalities and disordered steroidogenesis (OMIM 201750) [9, 21, 22]. Urinary steroid profile usually indicates combined CYP21 and CYP17 deficiency $[9,21,23]$, although the extent to which either enzyme is compromised varies according to the site of the POR mutation: the A287P variant is associated with preferential inhibition of 17 alpha hydroxylase and 17,20 lyase activity $[21,24]$, whereas variants located in the electron transfer area, e.g., Y181D, H628P, lead to equal impairment of CYP17 and CYP21 activities [24].

In contrast to these rare, enzyme-disrupting mutations, polymorphisms in the POR gene occur in up to one-third of the population and are associated with altered $P O R$ transcription and enzymatic activity [25-27]. In fact, both increased and reduced POR activity has been observed in liver samples from individuals carrying different $P O R$ variants [28] and, furthermore, the impact of $P O R$ polymorphisms appears CYP substrate-specific [29].

Given the high frequency of $P O R$ variants and its impact on CYP enzyme function, we hypothesized that $P O R$ may act as modifier gene, thereby contributing to the variability in genotype-phenotype correlation among patients with defects in 21 hydroxylase activity. Interestingly, a patient with coexisting POR and CYP21A2 defects had been described some 30 years ago [30]; genotyping revealed c.293-13A > G/P30L mutations on CYP21A2 and a A287P $P O R$ variant on the maternal allele- the most frequent variant among Caucasians [31]. Clinicians were struck by the mild, non-progressive virilization in context of severe, saltwasting 21 hydroxylase deficiency suggesting an impact of the heterozygous $P O R$ defect on clinical features of congenital adrenal hyperplasia.

We genotyped $P O R$ and identified eight variants spread across the $P O R$ gene, both intronic and exonic. All variants had been previously described and variant assessment by in silico predictive programs as well as literature searches allowed classification of intronic SNPs, i.e., rs41301394, rs4732516, rs2286822, and rs2286823, as well as the three synonymous SNPs, i.e., rs1135612, rs2228104, and rs 1057870 , as benign [17]. Conversely, the rs 1057868 polymorphism leads to an alanine-to-valine switch (i.e., p.A503V) and has been the focus of several studies under the moniker $P O R^{*} 28$. Studies in Asian as well as other populations have revealed an association of the variant with bladder cancer [32], post-kidney transplant diabetes [33], and hepatitis B virus-related hepatocellular carcinoma [20]. A small study evaluated p.A503V in 17 patients with either classic or non-classic adrenal hyperplasia [34], but was clearly underpowered to detect any association. This same study did not detect differences in normal 21 hydroxylase activity in vitro between wild-type and p.A503V POR transfectants; the effect of this polymorphism in mutated $C Y P 21 A 2$ remains to be established. Of note, $P O R$ variants have been mostly studied for their effect on CYP17 rather than CYP21 activity $[22,24]$.

Our data now provide evidence for the association between $P O R$ polymorphisms and clinical features of congenital adrenal hyperplasia, thereby establishing $P O R$ as a genetic modifier of $C Y P 21 A 2$ defects. POR polymorphisms appear to act both as primary and secondary genetic modifiers as the rs2228104 minor allele is associated with higher prevalence of non-classic adrenal hyperplasia and the rs2268622/rs2268623 minor alleles are associated with severity of clinical features in classic adrenal hyperplasia.

The rs2228104 polymorphism is a synonymous alanine variant on exon 13 (i.e., p.A485=), whose impact is as yet unknown. It lies within the FAD moiety and an alanineto-threonine variant at the same amino acid (p.A485T) is associated with reduced 17 hydroxylase/17,20 lyase activity [35]. A single study has so far evaluated the rs 2228104 polymorphism and reported no changes in POR synthesis or activity in liver specimens from individuals carrying different alleles [28]. Interestingly, minor allele frequency is low, i.e., $0.03-0.1 \%$, especially in Europeans, as shown in databases, e.g., Genome Aggregation Database, Broad Institute, and individuals studies including our own [27, 28] and, in fact, homozygous carriers of the minor allele (TT) appear to be extremely rare, even absent in some series [27, 28]. In our study, frequency of the minor allele among patients with non-classic adrenal hyperplasia was higher than expected, i.e., $11 \%$, and was associated with a sixfold higher risk of being affected by non-classic rather than classic congenital adrenal hyperplasia. The effect of rs 2228104 is reminiscent of primary modifier genes in thalassemia; indeed, KLF1 (Kruppel-like factor 1) variants are overrepresented among patients with thalassemia intermedia compared to thalassemia major [36]. Given that the POR gene is located on chromosome 7 and $C Y P 21 A 2$ on chromosome 6, linkage disequilibrium between rs2228104 and CYP21A2 mutations associated with non-classic 21 hydroxylase deficiency appears unlikely. It is tempting to speculate that this finding could be due to genetic drift or selection, if rs2228104 were to confer a selective advantage to the non-classic phenotype.

As regards the rs2268622/rs2268623 haplotype, our results showed an association with severity of clinical features among children with classic congenital adrenal hyperplasia. Newborns with the minor alleles presented a more severe presentation with greater prevalence of saltwasting and higher Prader stage in girls. This finding is of particular interest given that it reflects disease severity at presentation. In line with this evidence, higher plasma ACTH concentrations, albeit a measurement subject to considerable variability [37], and younger age at diagnosis were observed in carriers of the minor alleles. In 
our study, the dominant model proved statistically significant, indicating that the minor T/A alleles are associated with a more severe clinical presentation. In vitro studies on the rs2268622/rs2268623 alleles reported reduced POR protein and activity in liver samples from minor TT and AA genotypes [28], thus, although intronic, these sequence variants impact POR function. Our findings suggest that $P O R$ rs $2268622 / \mathrm{rs} 2268623$ are associated with greater impairment of CYP21 activity, thus more severe clinical presentation. In support of this hypothesis, the polymorphism was equally prevalent across severity of CYP21A2 mutation groups associated with classic congenital hyperplasia. Studies on the effect of this haplotype on 21 hydroxylase activity, with focus on severe enzymatic impairments such as those occurring with mutations leading to classic 21 hydroxylase deficiency [38], are needed to substantiate this hypothesis.

Congenital adrenal hyperplasia due to 21 hydroxylase deficiency is a severe endocrine genetic defect with good though not absolute genotype-phenotype correlation [1-3]. In fact, in vitro behavior of $C Y P 21 A 2$ mutations was not wholly predictive of the clinical phenotype [5] and attempts to predict the phenotype based on CYP21A2 mutations fall short of reliable prediction [11]. Premature pubarche and hirsutism, for example, are associated with different percentages of both severe and mild CYP21A2 mutations [39, 40]. Furthermore, a recent large-scale study reported that less than $50 \%$ of $C Y P 21 A 2$ genotypes presented the predicted phenotype [4] and confirmed evidence [5, 6], indicating that while some mutations are predominantly associated with either the salt-wasting or the simple virilizing phenotype, they may give rise to other disease phenotypes as well. POR polymorphisms may contribute this variability in clinical presentation with a given $C Y P 21 A 2$ defect, thus act as a secondary modifier gene [41], much like it occurs in other genetic disorders. One well-known example of such modifier genes is $T G F B 1$ in cystic fibrosis with specific variants associated with greater disease severity [42].

In conclusion, our study demonstrated that $P O R$ acts as a modifier gene in congenital adrenal hyperplasia due to 21 hydroxylase deficiency. POR polymorphisms are associated with predisposition to classic vs non-classic forms as well as severity of classic adrenal hyperplasia. POR polymorphisms may represent the basis of a more individualized approach to management of this disease.

Supplementary Information The online version contains supplementary material available at https://doi.org/10.1007/s40618-021-01527-2.

Funding Open access funding provided by Università degli Studi di Milano within the CRUI-CARE Agreement.. This research did not receive any specific grant from funding agencies in the public, commercial, or not-for-profit sector.
Availability of data and materials Datasets generated during the current study are available at ClinVar repository https://submit.ncbi.nlm.nih. gov/subs/clinvar_org/SUB7932923/

\section{Compliance with ethical standards}

Conflict of interest The authors declare that there is no conflict of interest.

Ethics approval The study was approved by the Ethical Committee of the Azienda Ospedaliera Città della Salute e della Scienza in Turin.

Consent to participate Written informed consent for secondary use of genomic samples was obtained from patients or parents of affected children.

Open Access This article is licensed under a Creative Commons Attribution 4.0 International License, which permits use, sharing, adaptation, distribution and reproduction in any medium or format, as long as you give appropriate credit to the original author(s) and the source, provide a link to the Creative Commons licence, and indicate if changes were made. The images or other third party material in this article are included in the article's Creative Commons licence, unless indicated otherwise in a credit line to the material. If material is not included in the article's Creative Commons licence and your intended use is not permitted by statutory regulation or exceeds the permitted use, you will need to obtain permission directly from the copyright holder. To view a copy of this licence, visit http://creativecommons.org/licenses/by/4.0/.

\section{References}

1. Speiser PW, Azziz R, Baskin LS, Ghizzoni L, Hensle TW, Merke DP, Meyer-Bahlburg HF, Miller WL, Montori VM, Oberfield SE, Ritzen M, White PC (2010) Congenital adrenal hyperplasia due to steroid 21-hydroxylase deficiency: an endocrine society clinical practice guideline. J Clin Endocrinol Metab 95:4133-4160

2. Miller WL, Auchus RJ (2011) The molecular biology, biochemistry, and physiology of human steroidogenesis and its disorders. Endocrine Rev 32:81-151

3. Einaudi S, Napolitano E, Restivo F, Motta G, Baldi M, Tuli G, Grosso E, Migone N, Menegatti E, Manieri C (2011) Genotype, phenotype and hormonal levels correlation in non-classical congenital adrenal hyperplasia. J Endocrinol Invest 34:660-664

4. New MI, Abraham M, Gonzalez B, Dumic M, Razzaghy-Azar M, Chitayat D, Sun L, Zaidi M, Wilson RC, Yuen T (2013) Genotypephenotype correlation in 1,507 families with congenital adrenal hyperplasia owing to 21-hydroxylase deficiency. Proc Natl Acad Sci USA 110:2611-2616

5. Speiser PW, Dupont J, Zhu D, Serrat J, Buegeleisen M, TusieLuna MT, Lesser M, New MI, White PC (1992) Disease expression and molecular genotype in congenital adrenal hyperplasia due to 21-hydroxylase deficiency. J Clin Invest 90:584-595

6. Chemaitilly W, Betensky BP, Marshall I, Wei JQ, Wilson RC, New MI (2005) The natural history and genotype-phenotype nonconcordance of HLA identical siblings with the same mutations of the 21-hydroxylase gene. J Pediatr Endocrinol Metab 18:143-153

7. Miller WL, Agrawal V, Sandee D, Tee MK, Huang N, Choi JH, Morrissey K, Giacomini KM (2011) Consequences of POR mutations and polymorphisms. Mol Cell Endocrinol 336:174-179 
8. Fluck CE, Pandey AV, Huang N, Agrawal V, Miller WL (2008) P450 oxidoreductase deficiency - a new form of congenital adrenal hyperplasia. Endocr Dev 13:67-81

9. Arlt W, Walker EA, Draper N, Ivosin HE, Ride JP, Hammer F, Chalder SM, Borucka-Mankiewicz M, Hauffa BP, Malunowicz EM, Stewart PM, Shackleton CHL (2004) Congenital adrenal hyperplasia caused by mutant P450 oxireductase and human androgen synthesis: an analytical study. Lancet 363:2128-2135

10. Napolitano E, Manieri C, Restivo F, Composto E, Lanfranco F, Repici M, Pasini B, Einaudi S, Menegatti E (2011) Correlation between genotype and hormonal levels in heterozygous mutation carriers and non-carriers of 21-hydroxylase deficiency. J Endocrinol Invest 34:498-501

11. Krone N, Braun A, Roscher AA, Knorr D, Schwarz HP (2000) Predicting phenotype in steroid 21-hydroxylase deficiency? Comprehensive genotyping in 155 unrelated, well defined patients from southern Germany. J Clin Endocrinol Metab 85:1059-1065

12. Koressaar T, Remm M (2007) Enhancements and modifications of primer design program Primer3. Bioinformatics 23:1289-1291

13. Schwarz JM, Cooper DN, Schuelke M, Seelow D (2014) MutationTaster2: mutation prediction for the deep-sequencing age. Nat Methods 11:361-362

14. Reva B, Antipin Y, Sander C (2007) Determinants of protein function revealed by combinatorial entropy optimization. Genome Biol $8: \mathrm{R} 232$

15. Ng PC, Henikoff S (2003) SIFT: Predicting amino acid changes that affect protein function. Nucleic Acids Res 31:3812-3814

16. Rogers MF, Shihab HA, Mort M, Cooper DN, Gaunt TR, Campbell C (2018) FATHMM-XF: accurate prediction of pathogenic point mutations via extended features. Bioinformatics 34:511-513

17. Richards S, Aziz N, Bale S, Bick D, Das S, Gastier-Foster J, Grody WW, Hegde M, Lyon E, Spector E, Voelkerding K, Rehm HL (2015) Standards and guidelines for the interpretation of sequence variants: a joint consensus recommendation of the American college of medical genetics and genomics and the association for molecular pathology. Genet Med 17:405-424

18. Barrett JC, Fry B, Maller J, Daly MJ (2005) Haploview: analysis and visualization of LD and haplotype maps. Bioinformatics 21:263-265

19. Rosner B (2016) Fundamental of biostatistics, 8th edn. Cengage Learning, Boston

20. Huang K, Liao X, Han C, Wang X, Yu T et al (2019) Genetic variants and expression of cytochrome $\mathrm{p} 450$ oxireductase predict survival in patients with hepatitis B virus-related hepatocellular carcinoma. J Cancer 10:1453-1465

21. Fluck CE, Tajima T, Pandey AV, Arlt W, Okuhara K, Verge CF, Jabs EW, Mendonca BB, Fujieda K, Miller WL (2004) Mutant $\mathrm{P} 450$ oxidoreductase causes disordered steroidogenesis with and without Antley-Bixler syndrome. Nat Genet 36:228-230

22. Huang N, Pandey AV, Agrawal V, Reardon W, Lapunzina PD, Mowat D, Jabs EW, Van Vliet G, Sack J, Fluck CE, Miller WL (2005) Diversity and function of mutations in p450 oxidoreductase in patients with Antley-Bixler syndrome and disordered steroidogenesis. Am J Hum Genet 76:729-749

23. Krone N, Reisch N, Idkowiak J, Dhir V, Ivison HE et al (2012) Genotype-phenotype analysis in congenital adrenal hyperplasia due to P450 oxidoreductase deficiency. J Clin Endocrinol Metab 97:E257-E267

24. Dhir V, Ivison HE, Krone N, Shackleton CH, Doherty AJ, Stewart PM, Arlt W (2007) Differential inhibition of CYP17A1 and CYP21A2 activities by the P450 oxidoreductase mutant A287P. Mol Endocrinol 21:1958-1968

25. Miller WL, Huang N, Agrawal V, Giacomini KM (2009) Genetic variation in human $\mathrm{P} 450$ oxidoreductase. Mol Cell Endocrinol 300:180-184
26. Burkhard FZ, Parween S, Udhane SS, Fluck CE, Pandey AV (2017) P450 Oxidoreductase deficiency: analysis of mutations and polymorphisms. J Steroid Biochem Mol Biol 165:38-50

27. Tomkova M, Panda SP, Seda O, Baxova A, Hulkova M, Siler Masters BS, Martasek P (2015) Genetic variations in NADPHCYP450 oxidoreductase in a Czech Slavic cohort. Pharmacogenomics 16:205-215

28. Zhang HF, Li ZH, Liu JY, Liu TT, Wang P, Fang Y, Zhou J, Cui MZ, Gao N, Tian X, Gao J, Wen Q, Jia LJ, Qiao HL (2016) Correlation of cytochrome $\mathrm{P} 450$ oxidoreductase expression with the expression of 10 isoforms of cytochrome P450 in human liver. Drug Metab Dispos 44:1193-1200

29. Fang Y, Gao N, Tian X, Zhou J, Zhang HF, Gao J, He XP, Wen Q, Jia LJ, Jin H, Qiao HL (2018) Effect of P450 oxidoreductase polymorphisms on the metabolic activities of ten cytochrome P450s varied by polymorphic CYP genotypes in human liver microsomes. Cell Physiol Biochem 47:1604-1616

30. Scott RR, Gomes LG, Huang N, Van Vliet G, Miller WL (2007) Apparent manifesting heterozygosity in P450 oxireductase deficiency and its effect on coexisting 21-hydroxylase deficiency. J Clin Endocrinol Metab 92:2318-2322

31. Pandey AV, Sproll P (2014) Pharmacogenomics of human P450 oxidoreductase. Front Pharmacol 5:103. https://doi.org/10.3389/ fphar.2014.00103

32. Xiao X, Ma G, Li S, Wang M, Liu N, Ma L, Zhang Z, Chu H, Zhang Z, Wang SL (2015) Functional POR A503V is associated with the risk of bladder cancer in a Chinese population. Sci Rep 5:11751. https://doi.org/10.1038/srep11751

33. Elens L, Sombogaard F, Hesselink DA, van Schaik RHN, van Gelder T (2013) Single-nucleotide polymorphisms in P450 oxireductase and peroxisome proliferator-activater receptor- $\alpha$ are associated with the development of new-onset diabetes after transplantation in kidney transplant recipients treated with tacrolimus. Pharmacogenet Genomics 23:649-657

34. Gomes LG, Huang N, Agrawal V, Mendonca BB, Bachega TA, Miller WL (2008) The common P450 oxidoreductase variant A503V is not a modifier gene for 21-hydroxylase deficiency. $\mathrm{J}$ Clin Endocrinol Metab 93:2913-2916

35. Huang N, Agrawal R, Giacomini KM, Miller W (2008) Genetics of P450 oxireductase: sequence variation of 842 individuals of four ethnicities and activities of 15 missense mutations. Proc Natl Acad Sci USA 105:1733-1738

36. Liu D, Zhang X, Yu L, Cai R, Ma X et al (2014) KLF1 mutations are relatively more common in a thalassemia endemic region and ameliorate the severity of beta-thalassemia. Blood 124:803-811

37. Pecori Giraldi F, Saccani A, Cavagnini F, the Study Group of the Italian Society of Endocrinology on the Pathophysiology of the Hypothalamic-Pituitary-Adrenal Axis (2011) Assessment of ACTH assay variability: a multicenter study. Eur J Endocrinol 164:505-512

38. Simonetti L, Bruque CD, Fernandez CS, Benavides-Mori B, Delea M, Kolomenski JE, Espeche LD, Buzzalino ND, Nadra AD, Dain L (2018) CYP21A2 mutation update: comprehensive analysis of databases and published genetic variants. Hum Mutat 39:5-22

39. Ghizzoni L, Cappa M, Vottero A, Ubertini G, Carta D et al (2011) Relationship of CYP21A2 genotype and serum 17-hydroxyprogesterone and cortisol levels in a large cohort of Italian children with premature pubarche. Eur J Endocrinol 165:307-314

40. Moura-Massari VO, Bugano DD, Marcondes JA, Gomes LG, Mendonca BB, Bachega TA (2013) CYP21A2 genotypes do not predict the severity of hyperandrogenic manifestations in the nonclassical form of congenital adrenal hyperplasia. Horm Metab Res 45:301-307

41. Dipple KM, McCabe ER (2000) Modifier genes convert "simple" Mendelian disorders to complex traits. Mol Genet Metab $71: 43-50$ 
42. Arkwright PD, Laurie S, Super M, Pravica V, Schwarz MJ, Webb AK, Hutchinson IV (2000) TGF- $\beta(1)$ genotype and accelerated decline in lung function of patients with cystic fibrosis. Thorax $55: 459-462$
Publisher's Note Springer Nature remains neutral with regard to jurisdictional claims in published maps and institutional affiliations. 